\title{
CORRELACIONES ENTRE LOS LENGUAJES FILOSÓFICOS CLÁSICO Y MEDIEVAL. (ECOS SILOGÍSTICOS OLVIDADOS DE ARISTÓTELES EN PEDRO HISPANO)
}

Fermín de Urmeneta

Muchos son los estudiosos que atribuyen a Pedro Hispano el haber formulado, por vez primera, en latín y desde sus célebres Súmulas logicales, las leyes propias de las tres figuras fundamentales del silogismo categórico. Sin embargo, tal atribución no resulta exacta, pues aun cuando es cierto que de tal obra derivan los habituales enunciados latinos, algo no menos indudable es que en las Prioridades analíticas del griego Aristóteles se ofrecen antecedentes casi literales de los mismos. Un posible cotejo, entre unos y otros textos, ofrecerá la mejor comprobación frente a lo acabado de afirmar: esto es lo que va a ser ofrecido a continuación mediante breve esquema, en cuyo seno se articularán los dos grupos básicos de leyes lógicas al respecto - las cuantitativas y las cualitativas-, para terminar con breves glosas en torno de las ideaciones de silogismo y demostración; y de su conjunto cabrá inferir, con toda seguridad, olvidadas y sugerentísimas correlaciones entre las lenguas filosóficas por excelencia, la griega y la latina.

\section{LEYES CUALITATIVAS}

Leyes de la primera figura

a) Fórmula hispaniana: «existiendo una premisa menor negativa, nada se sigue" (Summulae, 4. 06: minore existente negativa, nihil sequitur).

b) Fórmula aristotélica: «cuando los tres términos se conexionan entre sí de tal modo que el menor está por completo en el medio y el medio 
está o no está por completo en el mayor, entonces por necesidad habrá

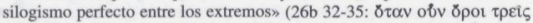

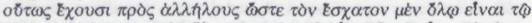

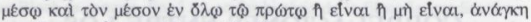

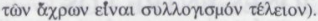

Leyes de la segunda figura

a) Fórmula hispaniana: «de dos premisas afirmativas, nada se sigue» (Summulae, 4, 10: e puris negativis, nihil sequitur).

b) Fórmula aristotélica: acuando lo mismo conviene a un todo y a su vez en nada conviene a otro, o por el contrario ese todo y esa nada se intercambian, entonces a tal figura la llamo segunda» (26b 34-36: $\delta \tau \alpha \mathrm{V}$

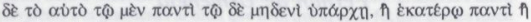

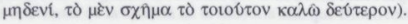

\section{Leyes de la tercera figura}

a) Fórmula hispaniana: кexistiendo una premisa menor negativa, nada se sigue (Summulae, 4. 13: minori existente negativa, nihil sequitur).

b) Fórmula aristotélica: «si frente a un mismo medio el menor le conviene totalmente y el mayor le repugna totalmente, o bien ambos se convienen totalmente $[\ldots]$ a tal figura la llamo terceras (28 a 10-12: $\varepsilon \dot{\alpha} v \mathrm{v}$

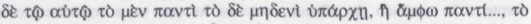

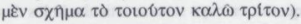

\section{LEYES CUANTITATIVAS}

Ante todo, adviértase cómo este segundo grupo de normas lo entronca Aristóteles con la conclusión, la cual a su vez depende siempre a estos efectos de la premisa mayor y nunca de la menor, según dan a entender las fórmulas de Pedro Hispano. Tras esta observación aclaratoria, prosigue nuestro esquema.

\section{Leyes de la primera figura}

a) Fórmula hispaniana: «existiendo una premisa mayor particular, nada se sigue» (Summulae, 4. 06: Maiore existente particulare, nihil sequitur). 
b) Fórmula aristotélica: «todos los problemas cabe mostrarlos mediante esta figura, pues en ella cabe concluir o con universalidad afirmativa, o con universalidad negativa, o con particularidad afirmativa, o con particularidad negativa, y por eso la llamo figura primeras (26b. 31-33:

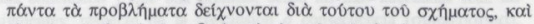

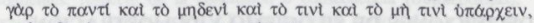

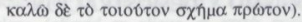

\section{Leyes de la segunda figura}

a) Fórmula hispaniana: «existiendo una premisa mayor particular, nada se sigue» (Summulae, 4, 10: maiore existente particulare, nihil sequitur).

b) Fórmula aristotélica: «no cabe silogismo afirmativo mediante esta figura, sino que todos son privativos, ora universales, ora particulares»

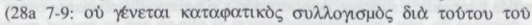

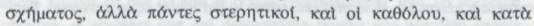
$\mu \varepsilon \hat{\rho} \rho \varsigma_{)}$.

(Aunque sólo sea entre paréntesis, y aun cuando me habia propuesto no interrumpir con exégesis personal ninguna el esquema silogístico que vengo ofreciendo, voy a permitirme aquí una excepción a tal propósito genérico y haré notar el enorme ímpetu creador que encarnan las expresiones aristotélicas acabadas de transcribir, las cuales acaso por sus excelencias intrínsecas debieron lograr alcanzar la resonancia multisecular que alcanzaron: en particular, estoy aludiendo - por un lado-a las ideas

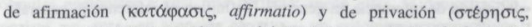
privatio), en cuanto concreciones máximas de la enunciación ( $\alpha \pi \delta \phi \alpha v \sigma \zeta \zeta$. enunciatio) y de la negación ( $\alpha \pi \delta \phi \alpha \sigma \iota \zeta$, negatio); y estoy aludiendo - por otro lado- a las expresiones antitéticas en universal ( $\alpha \alpha \theta 6 \lambda \circ \mathrm{v})$ y en particular ( $\kappa \alpha \tau \dot{\alpha} \mu \varepsilon \dot{\rho} \rho \zeta_{\text {) }}$, de no menor resonancia.)

\section{Leyes de la tercera figura}

a) Fórmula hispaniana: «no cabe conclusión, sino particulan» (Summulae, 4. 13: non concluiditur nisi particulare).

b) Fórmula aristotélica: «estructurar silogismos con universalidad

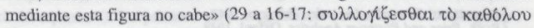

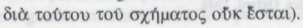


Ante ciertas sensibilidades acaso suenen algo extrañas las precedentes formulaciones. Más acaso por esto mismo convenía contrastar las recientes ediciones de las obras dialécticas de Pedro Hispano ${ }^{1}$ y de Aristóteles ${ }^{2}$.

\section{DEFINICIONES DE SILOGISMO Y DEMOSTRACIÓN}

En un lugar de sus Analíticos (24 a 27), plantéase Aristóteles el problema

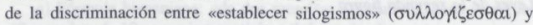
«establecer demostraciones» $(\alpha \pi \delta$ - $\delta \varepsilon t v 0 v \alpha t)$. Este esfuerzo discriminatorio resulta tanto más oportuno por cuanto, en el vocabulario aristotélico, con frecuencia estos verbos y sus derivaciones nominales son empleados como sinónimos. Pues bien, la solución aristotélica al problema ofrécese nítida y rotunda: a su tenor, demostración y silogismo diferéncianse como especie y género; o, si se prefiere, como lo particular de lo universal. Para proceder con orden, se atenderá aquí primero a lo genérico y luego a lo específico, a cuyo efecto,las reflexiones serán contrastadas con otras del máximo lógico medieval, el impar Pedro Hispano.

Según Aristóteles, «silogismo es el enunciado en el cual, desde ciertos presupuestos y concesiones, por necesidad obtiénese algo a partir de su

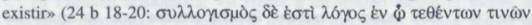

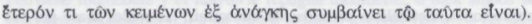
Comentando este precepto, el agudo W.S. Ross ${ }^{3}$ asevera que, en vez de una conceptualización del silogismo, lo que estas palabras ofrecen es una «definición de inferencia en general» (definition of inference in general). Esto mismo probablemente pensaría Pedro Hispano cuando, tras formular una noción del silogismo calcada en la aristotélica (oratio in qua quibusdam positis et concessis necesse est aliud accidere per ea quae posita sunt) - cual tributo de reverencia ante la autoridad del Estagiritano se contenta empero con ello, sino que se lanza a otra definición, más particularizadora, al tenor siguiente (Summulae, 4. 02): «enunciado en el cual, desde ciertos presupuestos en dos premisas o proposiciones, por necesidad surge algo que de ella se sigue, o sea la conclusión» (oratio in

\footnotetext{
I BORHENSKI, Summulae Logicales, Friburgo, 1947.

${ }^{2}$ Ross, Prior and Posterior Analytics, Oxford, 1948.

${ }^{3}$ Ross, op. cit. p. 35.
} 
qua quibusdam positis in duabus praemisis propositionibus necesse est aliud sequi per eas, id est conclusionem).

Por cierto que, entre las varias conceptualizaciones aristotélicas de qué es una conclusión y qué una premisa, acaso las más adecuadas sean las siguientes: respecto de la conclusión o consecuencia ( $\sigma u \mu \tau \varepsilon \rho \alpha \sigma \mu \alpha)$, aquélla de los Analíticos (53 a 8) que la define como «algo a partir de

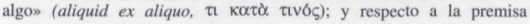
$(\pi \rho \sigma \tau \alpha \sigma \varsigma)$, aquélla de la Hermeneia ( 20 b 24$)$ que la conceptúa cual

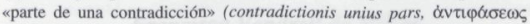
$\mu \mathrm{i} \alpha \xi_{\xi} \mu \delta \rho\llcorner o v)$. Una adaptación clarificadora de esta última idea es la ofrecida por la traducción que da de ella W.S. Ross, mediante esta locución: «una de las dos en un par de enunciaciones contradictorias» (one of a pair of contradictory statements).

Pasando ya de lo silogístico a lo demostrativo, recordaré ante todo los dos únicos lugares en que de ello se ocupa Pedro Hispano: uno, en acepción subjetiva, al sostener que «el demostrante prueba una afección propia respecto de un tema propion (Summulae, 7, 41: demonstrator propriam passionem probat de proprio subiecto); y otro, en acepción objetiva, al consignar-que ken cualquier demostración, las proposiciones son todas universales» (Summulae, 12.10: in qualibet demosnstratione, sunt omnes propositiones universales). Contrastando con esta parquedad, en la que no llega a plasmarse definición ninguna de lo demostrativo, gran amplitud es la desplegada por Aristóteles sobre el particular - al inicio de sus Proterioridades analíticas-, amplitud que le conduce a estructurar dos fórmulas nocionales a cuál más perfecta: según ellas, la demostración consiste en ser - en acepción efectiva - un «silogismo cognoscitivo»

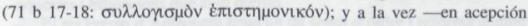

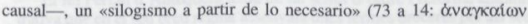

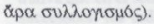

Por último, en la fórmula postrera apunta además otro sugestivo problema: el de la diversa vigencia de lo necesario en los silogismos y en las demostraciones. Mucho se ha escrito sobre el tema y con frecuencia sin claridad de ideas, pese a que Aristóteles acuño ya dos locuciones muy precisas para resolverlo. Me refiero a aquel lugar de su Órganon en el que

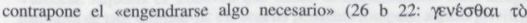

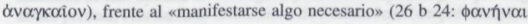

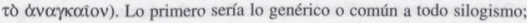
lo segundo, en cambio, sería lo específico o privativo de la demostración. 